\title{
Fisher ship present communication situation and the countermeasures
}

\author{
Jincai $\mathrm{He}^{\mathrm{a}}$, Wanzheng $\mathrm{Ai}^{\mathrm{b}}$ \\ Marine College of Zhejiang Ocean University, Zhoushan 316000, P. R. China
}

\begin{abstract}
This paper in recent years, commercial fishing vessel collision cases, the author analyzes the reasons of commercial fishing vessel collision, puts forward the coastal fishing area present situation and countermeasures of safe navigation.
\end{abstract}

\section{Analysis of fishing vessel safety communication current situation}

Through the analysis of the example above shows that compared with large merchant vessels, ordinary fishing boats sailing from crude instruments and communication equipments, poor performance. Most of the fishing boat insufficient investment in security infrastructure, safety equipment aging, and expiration phenomenon is widespread; especially communication navigation facility backwardness, the extreme weather and other dangerous situations can't meet the needs of communication and human assistance. Number of our country has built many fisheries shortwave coast station and ultra short wave coast station, part of the fishing boat is equipped with a shortwave radio and ultra short wave radio, and a lot of radio navigation and positioning equipment. Although China's fisheries foreign information acquisition and communication has been from the past single shortwave Morse telegraph, am radio telephone development to the present fishing with global navigation satellite (GPS)[1-2], the beidou satellite navigation system, fishing with wireless telephone, radar, ship automatic identification system (AIS), handheld two-way VHF (VHF) and digital selective calling (DSC), very high frequency in the emergency position indicating a standard (EPIRB), high-frequency SSB radio device (MF/HF/SSB), NAVTEX receiver, INMARSAT ship earth station (INMARSAT), search and rescue radar transponder (SART), satellite communications, CDMA communication, etc.; From the offshore communication extension to the ocean and global communication; From the past production command, emergency rescue communication for distress alerting, fisheries management, Marine meteorology, position monitoring, as well as the market situation, supply and injury treatment, various communication services such as life affairs. The merchant ship safety communication using the GMDSS (global maritime distress and safety system) [3-4], the use of satellite and ground communications technology, can effectively implement global, all-weather reliable secure communication. But given the Chinese fishing boat shortage of funds, the low cultural quality of the crew, difficult to use in boats satellite communication technology; Other Marine facing unprecedented adjustment of industrial structure in our country, some poor production efficiency, poor seaworthiness of fishing boats will phase out or transferred to civilian work, all of these factors affect the fishery communications system stability and the development of information network construction. Based on the above factors, the fishing boat FGMDSS full implementation of the system is not very realistic. However, with today's communication technology with advanced countries, China's Marine fisheries communication lags far behind the developed countries, in general, cannot satisfy the need of modern fishery production, management and security assistance. Mainly displays in: fishery communications construction lack of unified national development planning; Fisheries service areas scattered, sharing is poor, the overall function cannot be effectively play; Communication equipment, equipment aging, poor performance of service; Short-wave communication mode frequency is less, the quality of the communication is not high, management difficulties, more communication interference in a system, distress alerting range and reliability is not high, it can

\footnotetext{
a,b Corresponding author: ${ }^{\mathrm{a}} 1784218491 @ q q . c o m ;$

baiwanzheng@126.com
}

(C) The Authors, published by EDP Sciences. This is an open access article distributed under the terms of the Creative Commons Attribution License 4.0 (http://creativecommons.org/licenses/by/4.0/). 
only be in a certain range and the premise for fishing boats maritime security communication ability.

\section{Analysis and countermeasures}

In fishery production safety, prevent the happening of the danger and rescue after the appearance of danger, two main aspects are closely related to communication. Rainstorm, snowstorm, such as heavy fog weather alert need through the communication network is passed to the fishing boat at sea, the fishing boat to ready to cope with bad weather ahead of time, back to Hong Kong to circumvent or stay away from dangerous waters, and effectively prevent the happening of perils of the sea. When fishing vessels due to various reasons, the ship's personnel need emergency treatment, fishing boats need outside contact through communication network, to get timely treatment. When the ship itself a mechanical failure or damage, leading to problems of the traffic capacity of the ship of emergency, such as fishing boat launch emergency signals, ship or other land station learned that the vessel, to avoid further loss of the ship. If the ship is in distress, the crew can pass through communication equipment issued a distress signal, the ship and coast station around to hear distress information communication network, for the first time to take action to rescue, reducing the loss of life and property. So, if you want to pay special attention to the safety, must pay special attention to the communication. Secure communication network is set up and improve the fisheries, ensure smooth communication network, is to ensure the safety of maritime, an essential part of the emergency rescue measures.

1) The fishery radio communication into the public security system. At present, the fisheries production safety caused extensive concern of the government and fishing area society. Seeking the fishery economy and social development in the process, should the fishery radio communication as soon as possible into fishery public safety guarantee system, and provide powerful communication support for fisheries production safety. Formulates plans for the development of fishery radio as soon as possible, clear the development direction and development requirements. Want to increasing public investment in fisheries radio communication at the same time, to speed up the pace of communication infrastructure construction, improving fishery public security system. Coastal fisheries authorities at all levels to attach importance to and support the leadership of the fishery communications work, fully aware of fishery communications work in the fishery safety and the position and role of the socialist market economy, in order to better for fishery safety, fisheries production and fishery management services.
2) Ensure the effectiveness of communication. Secure communication and emergency rescue are two important fishery safety work part of section, to formulate feasible classified fishing boat rescue and relief provisions, clarify the responsibilities of various departments at all levels. Communication attendants once received the encounter risks main number, notify the security responsibility institution directly, in order to effectively organize rescue and relief work in time, minimize the fishermen's life and property losses. Coastal key fishery township and village (companies) to establish based on port fishery kiosk, implements formation production for boats, each team have a command of information Ship is given priority to, divided into different working channels, using radio communication, composed of maritime field information communication network; Communication is given priority to with kiosk, the land and sea and all commands his contact information, USES the single side band communication, and establish lateral contact with land each information point, county, Taiwan. In this way, fishing boats once the distress, groove in the time to contact, convenient for aid, communal and rescue.

3) Construction network operation platform in the set up and improve the communication network at the same time, should pay attention to establish and improve the network running public platform. Fishing is a disadvantaged industry and fishermen belong to vulnerable groups, under the existing conditions, all by individuals or fishing boat fishermen formation is responsible for the construction of fishery radio communication platform, is not conducive to the healthy development of the communication network. Provide a communication platform for fishermen, and communication running environment, shall be used as the government for the people an important work.

4) Technical standards to improve the formulation and implementation of communication equipment. Offshore fishing demand for radio communication presents the trend of more and more dependent on; the demand for data communication is becoming more and more urgent. And current fishery radio communications in the field of data communication in its infancy, with the development of technology and communication network for the perfection of offshore area coverage, data communications will enter a stage of rapid development, a large number of business information, security information and other value-added services will be able to enter the fishermen in the daily life of the masses through platform, its market prospects look good, some businesses must enter the market. Therefore, it is imperative that the standard first, to avoid detours. Suggest government experts on the basis of scientific reasoning, the relevant standards for fishery radio communication network and equipment, and take this opportunity to speed up the 
upgrade of the fishery radio communication network and digital transformation process, through the digital transformation, improve the quality of communication and expand information service function. In the aspect of hardware, should pay attention to the unity of the interface standard, such as power supply interfaces, antenna, audio interface and data interface, etc. In addition to the existing on the function of selective call and group call and scan function, must have automatic distress for help and response function, and even can be integrated necessary functions such as collision and darkroom. To fully consider the equipment and parts commonality, maintainability, makes every effort to do it easy installation, the price is reasonable. For the software system, should consider to upgrade existing analog channel for the demand of digital transmission channel, for voice and data signals sharing, cable and wireless interconnection specification. For data format, transport protocol, distress signal format, fishing boat, fishing boat status code database and application and so on also should draw up or use unified standard. In addition, to introduce market competition mechanism, encourage equipment manufacturers in accordance with the standards, developed communication equipment for fisheries, development suitable for the function modules of the existing equipment.

5) Strengthen the management of fishery radio communication. To promote to carry out the regulations on the administration of radio, and for the fishery radio management regulations enacted to create conditions. All kinds of Marine fishing boats to strictly in accordance with the requirements of the Marine fishing safety rules or radio communication equipment, and to do a good job with the maintenance training, make the equipment in good working condition, the application efficiency into full play. Actually according to the spirit of the regulations and the regulations, clear responsibilities and authorities, institutions in accordance with the law manage fisheries radio communication according to the characteristics of the fishing after system reform, advancing with The Times, broaden the management idea, explore under the new situation and the management of fishery radio methods and measures. Innovation order frequency assignment, station management, communication management and special equipment for the development and production supervision mechanism. For some problems in current fishery radio communication, neither rough a ban it, cannot be allowed to proceed unchecked and chaotic, but to strengthen the guide to achieve an orderly use. In communication operation management, training management functional departments should organize fishery radio communication, can use a fishery, substituting for the favorable opportunity of post crew training, organization boat station operation business training for personnel, conditional also promote fishery radio operator qualification system, improve their professional quality, enhance the professional ethics and legal consciousness, enable everybody to radio communication consciously abide by laws and regulations, jointly maintain good order of fishery radio communication. Great importance to the management organization setup and to personnel should be attached. Institutions, no matter how to reform the coastal cities as the above fishery administrative departments shall ensure that the fishery radio management functions, management professionals to be equipped with radio, there are conditions should also be equipped with radio professional and technical personnel.

6) Build continuous coverage of radio communication network. To classify for construction and upgrading, take a different technology to expand coverage, construction of offshore fishery radio communication network. Should be first guaranteed offshore of VHF and UHF frequency band within 50 miles offshore continuous coverage and all-weather communication, to ensure that the offshore fishing boat around the distress signal can be reliable receiving coast station or water search and rescue center. Such as wind and solar power, (including) of the islands with no residents on the island to establish unattended relay station; In fishing fleet when shipment carrier repeater; You can also set up cross section of the relay in offshore, the shortwave and ultra short wave network link. Through a series of technical reformation, offshore fishing dedicated communication network signal coverage to 100 nautical miles in a row, a variety of complementary network, stable and reliable signal of the target is achievable. In addition, the ship rafts communication is easily overlooked link, should establish communication channel between fishing boat and life raft, life-saving equipment, and should provide the communication security emergency rescue forces at site. Due to the fishery communications equipment are basically used FDMA frequency division multiple access technology, rising tensions in spectrum. So by both management and technology to improve spectrum efficiency, such as repeated by frequency assignment according to the different area, the appropriate frequency reuse methods, such as shortage of spectrum resources can effectively slow the solution of the contradiction; The fishing boat station into the country land station network, minimize spectrum abuse.

\section{Conclusion}

To improve the safety of Chinese fishing boats in the sea communication ability, needs the joint efforts of many sided, to long-term to place the production safety of the fishermen in important position, to strengthen the 
organization and leadership, give full play to the role of the existing equipment, set up and improve the fishery safety communication and information network. To combine fishery security, communications, information work and walk "to carry out the paid service of information, promote the fishery communications construction, to ensure the safety of fishery" way. To build China's offshore continuous coverage of the wireless communication network is an important basic work.

\section{References}

1. K.Y. Jiang, China's aquatic product. (1) in 2008.

2. J.X. Guo, Chinese library classification: F326.48 Document id code: A. Article number: 1009-(2006)06-0061-04.

3. X.G. Bao, W. Zhang, Z.Y. Yan, Navigation technology. 3, (2006).

4. Kaiyong Jiang, Yi Guo. China's aquatic product. 2, (2010). 